\title{
Vivaldi Antenna for RF Energy Harvesting
}

\author{
Jan SCHNEIDER ${ }^{1}$, Michal MRNKA ${ }^{2}$, Jan GAMEC ${ }^{1}$, Maria GAMCOVA ${ }^{1}$, Zbynek RAIDA ${ }^{2}$ \\ ${ }^{1}$ Dept. of Electronics and Multimedia Communications, Technical University of Košice, \\ Park Komenského 13, 04120 Košice, Slovak Republic \\ ${ }^{2}$ Dept. of Radio Electronics, Brno University of Technology, Technická 12, 61600 Brno, Czech Republic
}

jan.schneider@tuke.sk,xmrnka01@stud.feec.vutbr.cz,jan.gamec@tuke.sk,maria.gamcova@tuke.sk, raida@feec.vutbr.cz

Manuscript received November 13, 2015

\begin{abstract}
Energy harvesting is a future technology for capturing ambient energy from the environment to be recycled to feed low-power devices. A planar antipodal Vivaldi antenna is presented for gathering energy from GSM, WLAN, UMTS and related applications. The designed antenna has the potential to be used in energy harvesting systems. Moreover, the antenna is suitable for UWB applications, because it operates according to FCC regulations $(3.1-10.6 \mathrm{GHz})$. The designed antenna is printed on ARLON 600 substrate and operates in frequency band from $0.810 \mathrm{GHz}$ up to more than $12 \mathrm{GHz}$. Experimental results show good conformity with simulated performance.
\end{abstract}

\section{Keywords}

RF energy harvesting, UWB, Vivaldi antenna

\section{Introduction}

Energy harvesting is a functionality which generates a small amount of electrical power. Harvested energy from the environment can be reused to operate low-power electronic devices [2]. Waste energy could be harvested from light, heat, vibrations, radio waves etc. Only the radiofrequency $(\mathrm{RF})$ harvesting is discussed in this paper.

RF energy harvesting is a promising technology that can benefit from billions of radio transmitters around the world. Radio transmitters including mobile telephones, handheld radios, mobile base stations and television/radio broadcast stations are potential sources of RF energy [1].

A basic energy harvesting system consists of a receiving antenna and a rectification circuitry. The block diagram of an energy harvesting system is shown in Fig. 1 [3]. An efficient harvesting of RF energy requires an efficient antenna. The antenna gathers the RF energy from environment. Subsequently, the rectifier circuit converts the received RF signal into DC signal. The matching circuit provides efficient and matched transmission between the antenna and a RF-DC converter. The desired values of voltage are converted by a DC-DC converter. The required voltage gets to the load through the charging circuit.

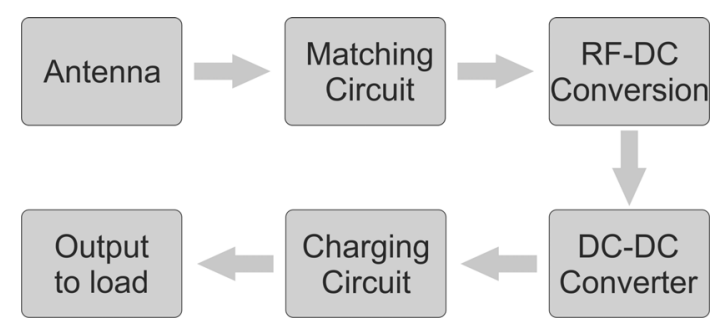

Fig. 1. Block diagram of the energy harvesting system.

The antennas for energy harvesting may be divided into several categories by the operating frequency band. The $900 \mathrm{MHz}$ slot-dipole antenna on a flexible substrate was discussed in [4]. In [5], the slot-dipole antenna was improved and integrated with energy harvesting circuit. Due to the narrow-band operation and the directive radiation, the slot-dipole antenna harvests energy from one source only.

In [6], a triple-band antenna combining three planar monopoles was introduced. Monopoles were tuned to $940 \mathrm{MHz}, 1.95 \mathrm{GHz}$ and $2.44 \mathrm{GHz}$. That way, RF energy from three different bands was able to be harvested. In [7], an equivalent concept is applied to dual-band harvesting.

Wideband antennas for energy harvesting have been published in [8] to [10]. Antennas were conceived as a fractal monopole [8], and wideband monopoles [9], [10].

Antennas for energy harvesting must satisfy a number of requirements. Antennas operating at desired frequencies and polarization are necessary. Preferred antennas are those that cover larger frequency bandwidth.

Special attention should be turned to UWB (Ultra Wide Band) antennas which could harvest energy from as wide frequency band as possible. Also, simple fabrication, low cost and practical usability of antennas should be considered. To meet the conditions, an antipodal Vivaldi antenna was selected for the purpose of this work. Even though the Vivaldi antenna is not omnidirectional, but wideband, it could harvest energy from a half-space where there are multiple wireless communications technologies.

In the open literature, exploitation of Vivaldi-like antennas in harvesting systems has been described [15]: the Vivaldi concept was applied to an amorphous silicon solar Vivaldi harvester. 
Similar design concepts of the Vivaldi antenna are presented in [16], where a novel compact end-fire antipodal Vivaldi antenna with bandwidth from $2 \mathrm{GHz}$ to more than $12 \mathrm{GHz}$ is proposed for ultra-wideband (UWB) applications e.g. radars, microwave imaging and in high data rate wireless systems. The antenna is proposed with bending microstrip line feed. The exponential slot of the proposed antenna is replaced by a sinusoidal modulated Gaussian tapered slot to improve the electrical length of the slot and to achieve a compact model of the antenna. Furthermore, in [17] the modified Compact Antipodal Vivaldi Antenna for $4-50-\mathrm{GHz}$ UWB applications is also presented. The paper presents two different loading structures - circular-shape-load and slot-load, where mentioned loads can dramatically improve the impedance bandwidth and achieve compact geometry. A simulated dual Vivaldi nanoantenna with infrared frequency bandwidth and high radiation efficiency for photonic applications is shown in [18]. The designed antenna is placed on Quartz substrate and operates as a pair instead of a single element. This approach allows to use two end-fire antennas placed opposite each other in order to get a peak gain in the antenna broadside direction.

The above mentioned antennas were designed for higher frequencies (more than $2 \mathrm{GHz}$ ). However, in lower frequency bands there are a lot of potential candidates of wireless services which can serve as sources of harvesting energy.

The design of an antipodal Vivaldi antenna for RF harvesting has not been published in the open literature yet.

Our basic assumption for energy harvesting is that the antenna fixed on a wall harvests energy, with a high probability, only from a half-space. Our intention was to design the most efficient method of converting electromagnetic energy from different sources of service providers (GSM, WLAN, WiMAX, radar, etc.).

A conventional frequency-domain characterization of the developed antenna (frequency response of return loss, radiation patterns at selected frequencies) is completed by a time domain characterization and its comparison with selected reference antennas.

\section{Antenna Design}

In this paper, a planar antipodal Vivaldi antenna for $\mathrm{RF}$ energy harvester is presented. Next sections present the design of the antenna for energy harvesting, the simulated and measured results.

We have chosen the frequency band satisfying UWB requirements (approximately from 0.81 to $10 \mathrm{GHz}$ ) to cover bands of the main wireless communications technologies such as GSM 900, GSM 1800, GSM 1900, UMTS 2.1, WLAN 2.4 GHz, WLAN 5, radio spectrum bands L, $\mathrm{S}, \mathrm{C}$ and more.

The configuration of the developed Vivaldi antipodal antenna for energy harvesting is shown in Fig. 2 together

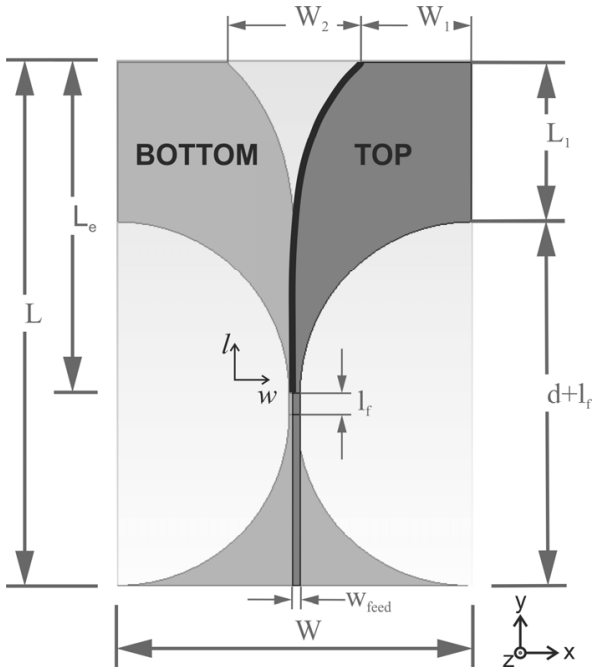

Fig. 2. Antipodal Vivaldi antenna with geometry parameters.

with the geometry parameters. The design objective is to obtain its compact size whilst maintaining the bandwidth requirement. The antenna consists of two coper layers; the top layer is connected to the signal conductor of the feeding line and the bottom layer is connected to the ground plane of the feeding line [11].

The designed UWB antipodal Vivaldi antenna for energy harvesting is printed on ARLON 600 substrate with relative permittivity $\varepsilon_{\mathrm{r}}=6.15$, loss tangent $\tan \delta=0.003$ and height of the substrate is $h=1.575 \mathrm{~mm}$ [12].

The width of the antenna $W$ is estimated by the lowest frequency of operation $f_{1}$ and by dielectric constant of the substrate $\varepsilon_{\mathrm{r}}$. The start value $W$ of the optimization process was stated by the equation [13]:

$$
W=\frac{c}{f_{1}} \sqrt{\frac{2}{\varepsilon_{\mathrm{r}}+1}} .
$$

Here, $c$ is the speed of light in free space, $f_{1}$ is the lowest operating frequency and $\varepsilon_{\mathrm{r}}$ is permittivity.

The appearance of inner side of the antenna arms (darker curve in Fig. 2) is based on the principle of exponential curves. Curve equation has the form (CST Microwave Studio uses analytical expressions of the following equation) [13]:

$$
l=\frac{L_{2}}{\sqrt[A]{W_{3}}} \cdot w^{\frac{1}{A}} .
$$

Here, the variables $A, L_{2}$, and $W_{3}$ affect the shape of the exponential curve described in coordinates $(w, l)$ according to Fig. 2.

The antenna arms are formed by connecting curves, such as lines $\left(W_{1}, L_{1}\right.$ etc.) and quarter circles (both sides of the line $l_{\mathrm{f}}$ ). Curves are designed in the same way by using the analytical curves. All statements curves of the antenna have their own variables. Variables were tuned and optimized in order to gain the required properties of the antenna. 
The width of the microstrip feed line $w_{\text {feed }}$ is calculated and matched to the characteristics impedance $Z_{0}=50 \Omega$.

\section{Simulated and Measured Results}

The design and verification of the functionality of the antenna was performed in the full wave electromagnetic simulator CST Microwave Studio (CST MWS) [14].

Curvature of the exponential curve of the arm, the mutual distance between the arms $W_{2}$ and the length of the arms (length of the darker curve in Fig. $2 L_{\mathrm{e}}$ ) were parameters that had the strongest impact on return loss and radiation pattern.

CST MWS was used for tuning and optimization of the parameters of the antenna. Algorithm of Trust region framework was used for the optimization of the final value of the parameters. The antenna was analyzed by the time domain solver. Optimized dimensions and final shape of the designed antenna with port by CST MWS are shown in Tab. 1 and in Fig. 3. The port was included in the simulation model.

The simulation results are depicted in the charts for direct comparison between simulation and measurement. The frequency responses of the magnitude of return loss at the input of the simulated antenna and the measured antenna are depicted in Fig. 4. The far field radiation pattern and return loss of the considered antenna were measured by a network vector analyzer in a rectangular anechoic chamber operating in range from tens of $\mathrm{MHz}$ to $20 \mathrm{GHz}$.

The value of the simulated return loss is below $10 \mathrm{~dB}$ above $1.2201 \mathrm{GHz}$. For the measured antenna, the value of return loss is below $10 \mathrm{~dB}$ above $0.810 \mathrm{GHz}$ with two small acceptable variations.

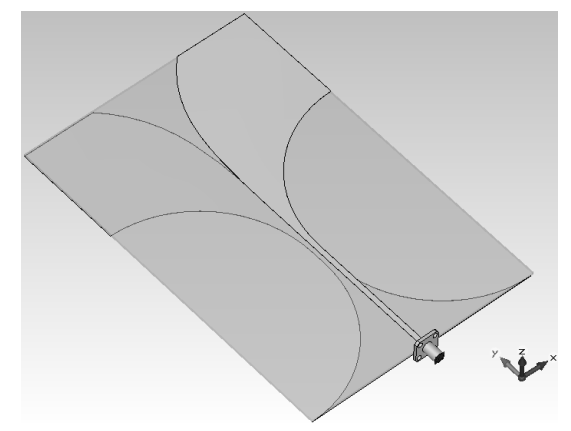

Fig. 3. Designed antenna with port in CST Studio.

\begin{tabular}{|l|r|l|r|}
\hline$W$ & $128.01 \mathrm{~mm}$ & $L_{1}$ & $58.00 \mathrm{~mm}$ \\
\hline$W_{1}$ & $39.55 \mathrm{~mm}$ & $l_{f}$ & $8.00 \mathrm{~mm}$ \\
\hline$W_{2}$ & $48.94 \mathrm{~mm}$ & $w_{\text {feed }}$ & $2.75 \mathrm{~mm}$ \\
\hline$L$ & $190.01 \mathrm{~mm}$ & $d$ & $124.00 \mathrm{~mm}$ \\
\hline$A$ & $400 \mathrm{~mm}$ & $L_{2}$ & $120 \mathrm{~mm}$ \\
\hline$W_{3}$ & $25.2 \mathrm{~mm}$ & & \\
\hline
\end{tabular}

Tab. 1. Optimized dimensions of the designed antenna.

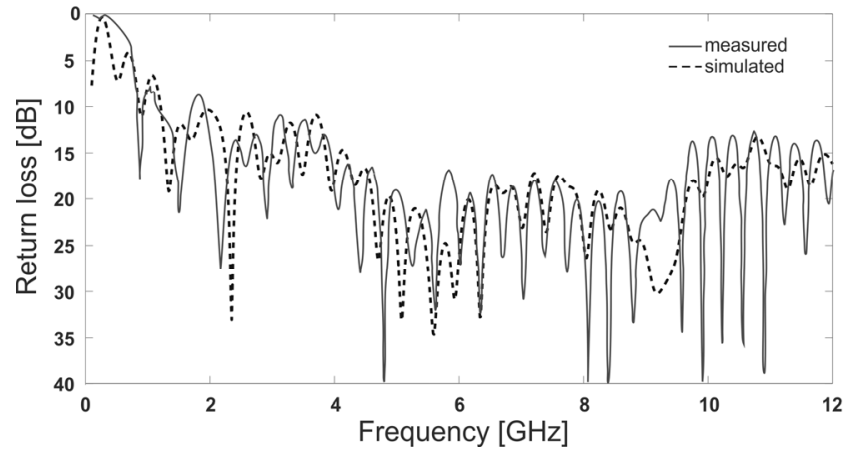

Fig. 4. Return loss of measured and simulated antenna.

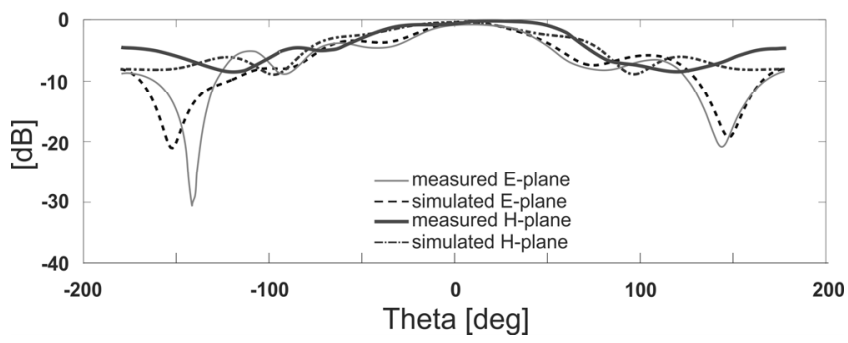

Fig. 5. Simulated and measured radiation patterns at $2 \mathrm{GHz}$.

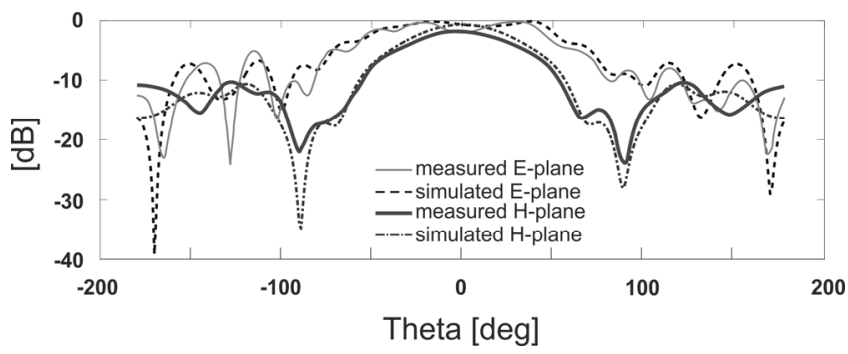

Fig. 6. Simulated and measured radiation patterns at $4 \mathrm{GHz}$.

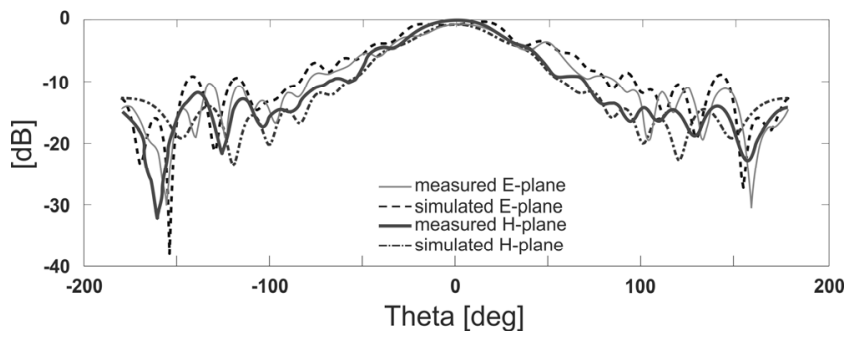

Fig. 7. Simulated and measured radiation patterns at $6 \mathrm{GHz}$.

The simulation and measurement results of radiation patterns for frequencies $2 \mathrm{GHz}, 4 \mathrm{GHz}$ and $6 \mathrm{GHz}$ are shown in Fig. 5 - Fig. 7, where E-plane is X-Y plane and $\mathrm{H}$-plane is $\mathrm{Y}-\mathrm{Z}$ plane.

The designed Vivaldi antenna was measured in the time domain by a pulse UWB radar and compared with the commercial wideband antennas:

- Double ridged waveguide horn: RFspin DRH10 (0.74 to $10.5 \mathrm{GHz}$ ),

- Small bow-tie: GEOZONDAS AU - 1.0G4.5GR (1.0 to $4.5 \mathrm{GHz}$ ),

- Large bow-tie: GEOZONDAS AU - 0.8G2.4G-B (0.8 to $2.4 \mathrm{GHz})$. 
The pulse UWB radar transmits a narrow pulse with the following parameters: Peak amplitude $U<30 \mathrm{~V} / 50 \Omega$ and width $t<50$ ps. Reflected signals were acquired from the antenna after adjusting of observation window of the scope according to the lengths of line $a$ and $b$. The shape and reference position of the excitation signal which is entering to the antenna were obtained by replacing the antenna with the calibration probe of type OPEN.

Principle diagram of measurement is shown in Fig. 8.

The pulse characteristics of the proposed Vivaldi antenna and commercial antennas are shown in Fig. 9 to Fig. 12. In these figures the exciting impulses are inserted. The exciting impulses are drawn to evaluate time relations of the measured signals, so the scale of the exciting impulse is reduced.

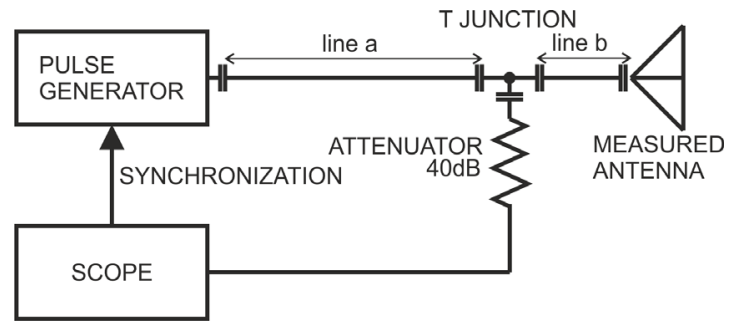

Fig. 8. Block diagram of measurement with the pulse UWB radar.

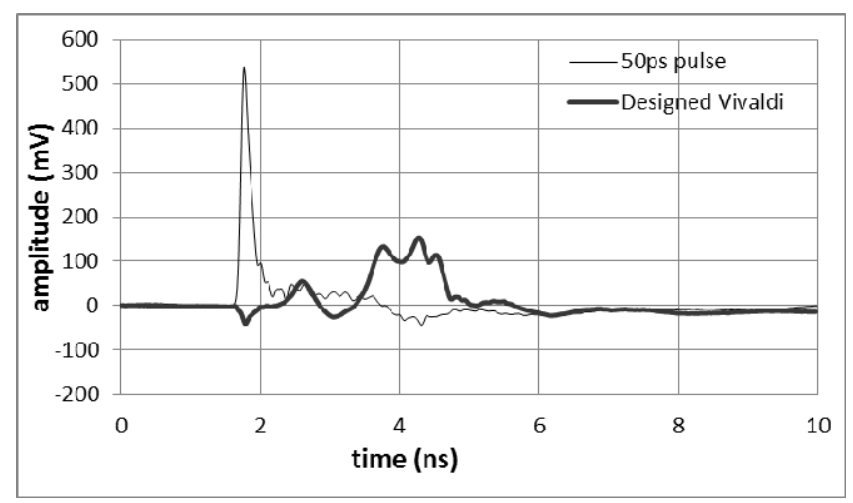

Fig. 9. Reflected response of manufactured Vivaldi antenna on exciting pulse.

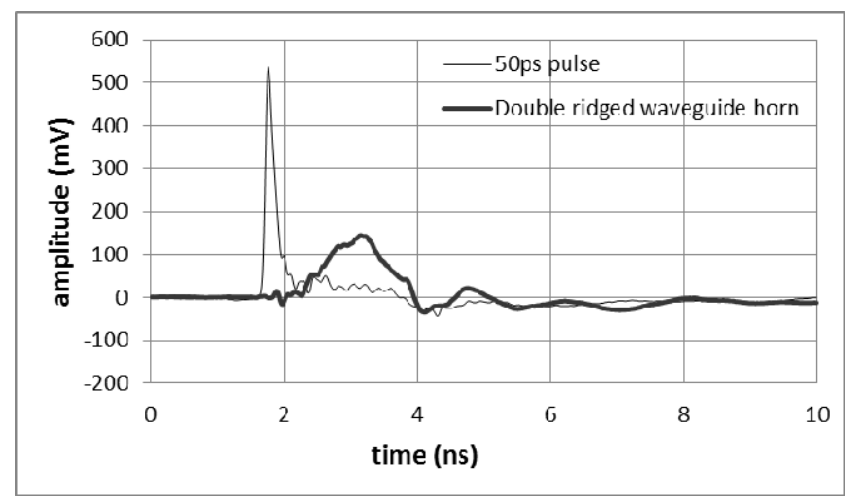

Fig. 10. Reflected response of double ridged waveguide horn antenna on exciting pulse.

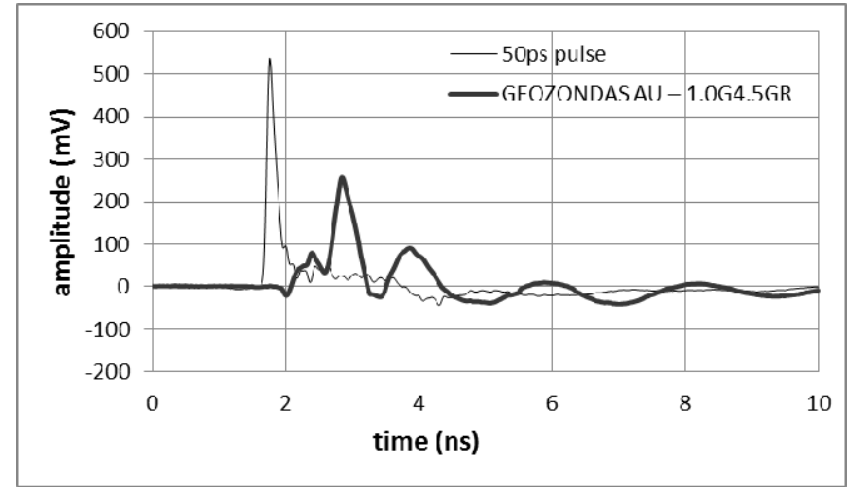

Fig. 11. Reflected response of GEOZONDAS AU -1.0G4.5GR on exciting pulse.

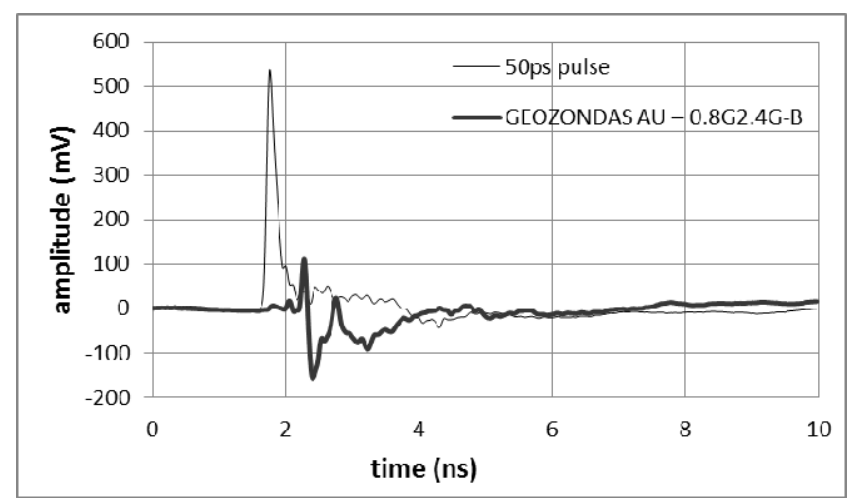

Fig. 12. Reflected response of GEOZONDAS AU-0.8G2.4G-B on exciting pulse.

\section{Conclusion}

The suitable antipodal Vivaldi antenna for RF energy harvesting was presented in this paper. The antenna was designed in the software CST Microwave Studio and the final dimensions of the antenna were obtained using optimization methods that are offered in this program. The manufactured antenna is depicted in Fig. 13.

The antenna operates in the frequency band from $0.8 \mathrm{GHz}$ to $12 \mathrm{GHz}$ with average gain $6.32 \mathrm{dBi}$ and fractional bandwidth $B W=163 \%$. Return loss of the antenna

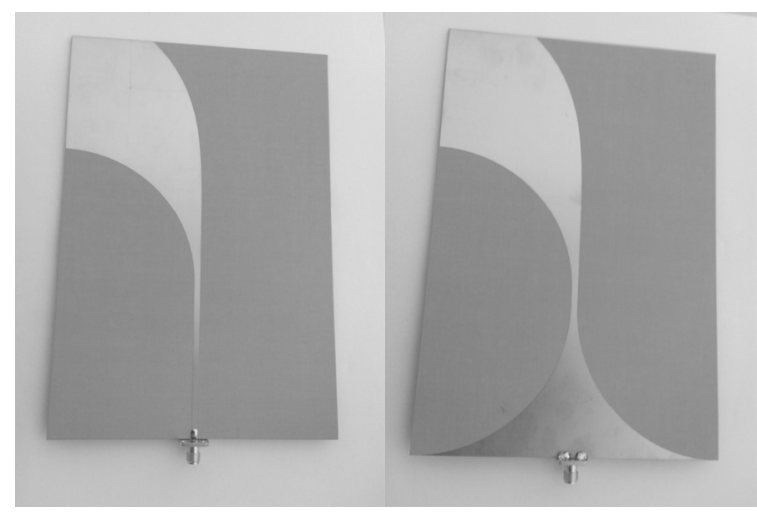

Fig. 13. Manufactured antenna. 
between 0.8 to $2 \mathrm{GHz}$ varies around the value $10 \mathrm{~dB}$ (Fig. 4). This small variation is acceptable for energy harvesting and UWB requirements. The antenna covers the frequency bands of multiple wireless communication systems. The measurement results confirmed simulated results.

The reflected impulse responses (Fig. 9 to Fig. 12) of the designed Vivaldi antenna have satisfactory frequency character in the wide bandwidth applications. Positive feedback from measurements in the time domain is the antenna has a very low ringing in comparison with commercially available antennas. The results presented above predestinates this antenna not only for the RF energy harvesting but also for applications sensitive to changes in group delay receiving and transmitting signal e.g. for UWB radars.

Wide bandwidth of the designed antenna and its relatively small size with low cost fabrication provide appropriate properties for the use in energy harvesting. The antenna might be used as an element of the antenna array to obtain a high gain and preserve a very high frequency bandwidth. The designed antenna can be used for RF energy harvesting and obtained RF energy can be reused to operate low-power electronic devices.

\section{Acknowledgments}

The research described in this paper was supported by the COST Action IC1301 WiPE Wireless Power Transmission for Sustainable Electronics, Scientific Grant Agency of the Ministry of Education of the Slovak Republic (ME SR) and of the Slovak Academy of Sciences (SAS) under the contract No.1/0563/13, the Slovak Research and Development Agency under the contract No. APVV-0404-12 and the Czech Ministry of Education under grant no. LD14057. For simulations and measurements, infrastructure of the SIX Research Center was used (support of the grant LO1401 INWITE is gratefully acknowledged).

\section{References}

[1] VAlENTA, C. R., DURGIN, G. D. Harvesting wireless power: survey of energy-harvester conversion efficiency in far-field, wireless power transfer systems. IEEE Microwave Magazine, 2014, vol. 15, no. 4, p. 108-120. DOI: 10.1109/MMM.2014.2309499

[2] ZUNGERU, A. M., et al. Radio frequency energy harvesting and management for wireless sensor networks. Green Mobile Devices and Networks: Energy Optimization and Scavenging Techniques, 2012, p. 341-368. DOI: 10.1201/b10081-16

[3] ZAKARIA, Z., ZAINUDDIN, N. A., ABD AZIZ, M. Z. A., et al. Dual-band monopole antenna for energy harvesting system. In IEEE Symposium Wireless Technology and Applications (ISWTA). Kuching (Malaysia), 2013, p. 225-229. DOI: 10.1109/ISWTA.2013.6688775
[4] HIRABARU, T., KANAYA, H., KANEMOTO, D., et al. Development of $900 \mathrm{MHz}$ band one-sided directional antenna on flexible substrate. In IEEE International Symposium Antennas and Propagation (APSURSI). Spokane (USA), 2011, p. 1008-1011. DOI: 10.1109/APS.2011.5996449

[5] KANAYA, H., TSUKAMAOTO, S., HIRABARU, T., et al. Energy harvesting circuit on a one-sided directional flexible antenna. IEEE Microwave and Wireless Components Letters, 2013, vol. 23, no. 3, p. 164-166. DOI: 10.1109/LMWC.2013.2246779

[6] PHAM, B. L., PHAM, A.-V. Triple bands antenna and high efficiency rectifier design for RF energy harvesting at 900, 1900 and $2400 \mathrm{MHz}$. In IEEE MTT-S International Microwave Symposium Digest (IMS). 2013, p. 1-3. DOI: 10.1109/MWSYM.2013.6697364

[7] BORGES, L. M., BARROCA, N., SARAIVA, H., et al. Design and evaluation of multi-band RF energy harvesting circuits and antennas for WSNs. In 21st International Conference Telecommunications (ICT). Lisbon (Portugal), 2014, p. 308-312. DOI: $10.1109 /$ ICT.2014.6845129

[8] TAGHADOSI, M., ALBASHA, L., QADDOUMI, N., et al. Miniaturised printed elliptical nested fractal multiband antenna for energy harvesting applications. IET Microwaves, Antennas \& Propagation, 2015, vol. 9, no. 10, p. 1045-1053. DOI: 10.1049/iet-map.2014.0744

[9] ZAINUDDIN, N. A., ZAKARIA, Z., HUSAIN, M. N., et al. Design of wideband antenna for RF energy harvesting system. In $3 r d$ International Conference on Instrumentation, Communications, Information Technology, and Biomedical Engineering (ICICI$B M E$ ). Bandung (Indonesia), 2013, p. 162-166. DOI: 10.1109/ICICI-BME.2013.6698485

[10] SAGHLATOON, H., BJORNINEN, T., SYDANHEIMO, L., et al. Inkjet-printed wideband planar monopole antenna on cardboard for RF energy-harvesting applications., IEEE Antennas and Wireless Propagation Letters, 2015, vol. 14, p. 325-328. DOI: 10.1109/LAWP.2014.2363085

[11] SAFATLY, L., et al. A reduced-size antipodal Vivaldi antenna with a reconfigurable band notch. In Progress In Electromagnetics Research Symposium Proceedings (PIERS). Moscow (Russia), 2012, p. 220-224. ISBN: 9781934142226

[12] ARLON MICROWAVE MATERIALS, AD600 (datasheet). 4 pages. [Online] Cited 2015-10-26. Available at: http://www.pwcircuits.co.uk/AD600.pdf

[13] ABBOSH, A. M., KAN, H. K., BIALKOWSKI, M. E. Design of compact directive ultra wideband antipodal antenna. Microwave and Optical Technology Letters, 2006, vol. 48, no. 12, p. 2448 to 2450. DOI: $10.1002 /$ mop. 21955

[14] Computer Simulation Technology (CST), CST Microwave Studio. [Online] Cited 2015-10-26. Available at: https://www.cst.com/Products/CSTMWS. 2015

[15] O'CONCHUBHAIR, O., YANG, K., MCEVOY, P., et al. Amorphous silicon solar Vivaldi antenna. IEEE Antennas and Wireless Propagation Letters, 2015, vol. 15, p. 893-896. DOI: 10.1109/LAWP.2015.2479189

[16] PANDEY, G. K., VERMA, H., MEShraM, M. K. Compact antipodal Vivaldi antenna for UWB applications. IET Electronics Letters, 2015, vol. 51, no. 4, p. 308-310. DOI: 10.1049/el.2014.3540

[17] BAI, J., SHI, S., PRATHER, D. W. Modified compact antipodal Vivaldi antenna for $4-50-\mathrm{GHz}$ UWB application. IEEE Transactions on Microwave Theory and Techniques, 2011 vol. 59, no. 4, p. 1051-1057. DOI: 10.1109/TMTT.2011.2113970

[18] ILUZ Z., BOAG, A. Wideband dual Vivaldi nano-antenna with high radiation efficiency over the infrared frequency band. In IEEE International Conference on Microwaves, Communications, 
Antennas and Electronics Systems (COMCAS). Tel Aviv (Israel), 2011, p. 1-3. DOI: 10.1109/COMCAS.2011.6105818

\section{About the Authors ...}

Ján SCHNEIDER was born in Košice, Slovakia, in 1988. He received Ing. (MSc.) degree in 2013 at the Department of Technology in Electronics, Faculty of Electrical Engineering and Informatics, Technical University in Košice. His thesis title was "Vibration test in electronics". Since September 2013 he has been with the Department of Electronics and Multimedia Communications, Technical University in Košice as a Ph.D. student. His research interests are antennas, UWB radars and LTCC.

Michal MRNKA was born in 1989 in Trnava, Slovakia. $\mathrm{He}$ received his Bc. (B.Sc.) and Ing. (M.Sc.) degrees in Electronics and Communications from Brno University of Technology in 2010 and 2013, respectively. Currently, he is working towards the Ph.D. degree in the same field. In 2013-2014 he worked as a research intern at Max Planck Institute for Radio Astronomy in Bonn, Germany. His research interests include analysis and design of antennas and microwave components and microwave measurements.

Ján GAMEC graduated (MSc) in 1985 with distinction at the Department of Radio Electronics, Faculty of Electrical Engineering and Informatics, Technical University in Košice. He defended his Ph.D. in the field of Radio Electronics in 1995. Currently he is an associated professor at the Department of Electronics and Multimedia Communi- cations, Faculty of Electrical Engineering and Informatics, Technical University in Košice. His main area of scientific research is digital image processing and UWB radar signal processing.

Mária GAMCOVÁ graduated in 1989 (MSc) with distinction at the Dept. of Radio Electronics, Faculty of Electrical Engineering and Informatics, Technical University in Košice. She defended her Ph.D. in the field of Telecommunications in 2005; her thesis title was "Nové algoritmy obnovy zašumených vektorov pohybu na báze č́slicovej filtrácie“. Since 1991 she has been teaching at the Dept. of Electronics and Telecommunications. Her actual scientific research focuses on sensor networks and wireless communications technologies for automobiles.

Zbyněk RAIDA was born in 1967 in Opava. He received his Ing. degree and Dr. degree from Brno University of Technology (BUT) in 1991 and 1994, respectively. In 1996-1997, he was with the Laboratoire de Hyperfrequences, Universite Catholique de Louvain, Belgium, working on variational methods of numerical analysis of electromagnetic structures. In 2006-2013, he was the head of the Dept. of Radio Electronics, and in 2010-2015 the head of the SIX Center. At present, he is a professor at the Dept. of Radio Electronics, Faculty of Electrical Engineering and Communication, BUT. His research interests cover numerical modeling and optimization of electromagnetic structures, exploitation of artificial neural networks for solving electromagnetic compatibility issues, and the design of special antennas. Zbyněk Raida is a member of IEEE Microwave Theory and Techniques Society. 